\title{
Nytt sätt att förstå suicidalitet?
}

\author{
Vid Jan Beskow och Anne Marie S. Johnsen
}

\section{Suicidalitet ses som ett symtom vid depression. Men kanske är det tvärtom. Kanske är depressionen snarare en följd av suicidalitet. Gradvis uppträdande förskjutningar har ändrat det suicidologiska forskningsfältet. Kanske står vi på tröskeln till en ny förståelse? Ett perspektiv som ser suicidalitet som en normal, funktionell reaktion och suicidhandlingar som en följd av psykologiska olycksfall. Suicidpreventionens främsta uppgift blir då att skapa ett mer nyanserat vardagsspråk om suicidalitet, suicidalitetens språk.}

\section{Övergripande resonemang om självmord}

Att vilja döda sig själv har under årtusenden uppfattats som skrämmande och obegripligt. Många olika resonemang, diskurser, har utvecklats om detta (Retterstöl, 2002; Beskow \& Jarrick, 2000). De finns fortfarande alla bland oss och påverkar oss mer än vi vanligen förstår. De har också skapat dagens forskningsparadigm.

Sammantaget har dessa resonemang beskrivit en sick-sack-rörelse allt närmare in mot den suicidala personens egna upplevelser. Starten var 300-talets religiöst motiverade självmordsförbud. Djävulen var aktör, den suicidala personen var övertalad. Detta följdes under 1800-talet av det på stoicismen grundade och genom avkriminaliseringen breddade moraliska perspektivet: Rätt/fel? Modigt/fegt? Den suicidala personen var själv ansvarig aktör. 1900-talets psykiatriska perspektiv utgick från psykisk sjukdom, främst depression, som riskfaktor och skapade farmakologiska behandlingsmöjligheter med suicidpreventiva effekter. Den suicidala personen var drabbad av sjukdom. Den suicidala processen (Pokorny, 1974; Beskow, 1979 och 1982) skapades senare på 1900 talet. Den band samman suicidtankar, suicidförsök och fullbordade suicid till en förståelig enhet och tydliggjorde betydelsen av omedvetna processer, suicidala meddelanden och krisinterventioner. De senaste decennierna har forskningen alltmer fokuserat på suicidalitetens kognitiva sida (Ellis, 2006). Den suicidala personen kan tränas att förstå och hantera sin suicidalitet.

Den historiska utvecklingen pekar således allt djupare in mot den suicidala patientens eget stormiga inre flöde. Om detta vet hon själv bäst besked. Kognitiva terapeuter uppfattar därför klienten som en fullvärdig medarbetare. Som två forskare angriper de ett gemensamt problem. Klienten bidrar med sin erfarenhet av sig själv, terapeuten med sina teorier och tekniker. På samma sätt kan den suicidala personen bli en betydelsefull medarbetare i forskningsteamet. I denna artikel bidrar därför Anne Marie S. Johnsen (AMSJ) med personlig erfarenhet av först frigörande, sedan plågsamt begränsande suicidtankar. För denna tidskrifts läsare är hon känd genom Ingeborg Veas intervju " Dødelig skam" (Vea, 2006). Jan Beskow (JB) bidrar med nyare teorier från suicidforskning och kognitiv psykoterapi.

\section{Dödande kränkning}

I høstm $\varnothing$ rket under en stor veibro ble jeg, AMSJ, overfalt og voldtatt av tre ukjente gjerningsmenn. Denne katastrofen forandret livet mitt. Jeg var 20 år.

$\AA$ dø. Jeg var helt overbevist om at "Nå dør jeg”, ”Nå er jeg død.” Ikke slik at jeg trodde de konkret skulle drepe meg, det hadde jeg ingen bevisst tanke om, og det var på en måte likegyldig hvordan det kom til å skje. Men jeg var overbevist om at dette ikke kunne overleves, at hjertet ville slutte å slå, at åndedrettet ville stoppe opp, enten jeg ble kvalt, slått ihjel eller kroppen som organisme brøt sammen. Når jeg døde ville det endelig, endelig, endelig være over.

Jeg opplevde en slags lammelse både psykisk og fysisk, og at kropp og sjel ikke var konstruert for å tåle en slik skade. Og mitt indre jeg, jeg selv, ble helt pulverisert/smadret/knust og døde der. Det kjentes veldig konkret. ”Nå dør Anne Marie. Her er bare en kropp igjen. La dem bare holde på. Jeg er død allerede”. Jeg hadde фynene åpne nesten hele tiden, jeg ville være bevisst når mørket og den fysiske døden kom.

Etter at jeg hadde ordnet meg så godt jeg kunne og samlet sammen sakene mine, gikk jeg hjem til hybelen (45 min.). Jeg gikk inn på badet og så meg i speilet. Det var bare et tomt skall som stirret tilbake. En ukjent. Jeg så en levende $\mathrm{d} \varnothing \mathrm{d}$.
Jeg hadde gått i stykker og kunne aldri bli meg selv igjen. Det var en fremmed som stod der og så på meg fra speilet.

Da jeg så speilbildet, kom tanken umiddelbart: "Jeg skal klare dette her så lenge det går. Det finnes andre som har vært utsatt for verre ting og som lever videre. Det skal jeg også. Så lenge ingen andre vet, kan jeg klare det.... Når, ikke hvis, jeg ikke klarer mer, tar jeg livet mitt."

Det som hendte, kan beskrives som en indre eksplosjon: Fysiske reaksjoner, bilder, tanker, overbevisninger, planer. Etterfulgt av følelsen av lammelse og $\mathrm{d} \varnothing \mathrm{d}$. $\AA$ leve videre var bare mulig dersom selvmordet fantes som en utvei.

Mye senere forsto jeg at dette førte til et posttraumatisk syndrom med mareritt og redsel. Skammen gjaldt først selve voldtektene, men etter hvert spredte den seg over hele livet mitt. Depresjonen var der fra begynnelsen, men symptomene kom senere. Jeg håndterte livet gjennom å dele meg i et forstilt, falskt, behersket ytre, og et sant, fortvilet indre.

A overleve. Beslutningen om at jeg kunne ta livet mitt var dermed en forutsetning for å kunne leve. Når presset, stresset ble for stort, var det en mental hvile å tenke på selvmordet som en utvei, tanken ble et sted å søke tilflukt. Det er den løsningen, den retten man har i en krigssituasjon som spion. Du har en kapsel cyan-

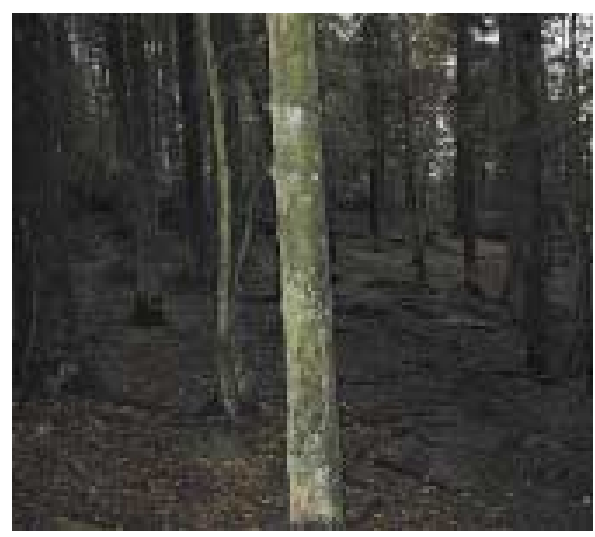


kalium med deg, og med den kan du redde deg ut av en hăpløs situasjon. N oen ganger var det godt å tenke tanken. D en gav meg fred eller en følelse av kontroll. U nder det ytre lå all smerte og skam begravd, det som var sant, men undertrykt. Det var så slitsomt og vanskelig å leve i spenningen mellom det som var sant, men skjult, og det som var falskt, men synlig. $\mathrm{N}$ år det ble for vanskelig, var selvmordstankene et tillfluktssted. De gav meg et pustehull, et sted der jeg kunne være meg selv. $0 \mathrm{~g}$ så gå ut i verden igjen......

G jennom legebesøk fikk jeg reseptbelagt paracetamol som jeg samlet til selvmordet. Til å begynne med var tablettene en trøst, de representerte en utvei, og jeg opplevde en slags kontroll. M en litt etter hvert ble de en trussel. Slik var det også med selvmordstankene. Fra å være et sted der jeg kunne søke tilflukt, ble de etter hvert en selvstendig trussel som trengte seg på. Tankene dukket hyppigere, sterkere og "ubedt" opp i de forskjelligste situasjoner

Jeg søkte hjelp hos lege og hos psykolog. De tok ikke tak i det smertegenererte traumet og var ikke til hjelp.

Ti år etter voldtektene opplevde jeg ytterlige store traumer og også en ikke planlagt graviditet. Depresjon og suicidrisiko tiltok og fikk meg til slutt til å søke hjelp igjen. Denne gangen ble jeg henvist til det som viste seg å være en klok, modig og faglig dyktig psykoterapeut. En jordmor med spesialkompetanse forberedte meg på og hjalp meg gjennom fødselen, og et personlig tilpasset rehabiliteringsopplegg førte meg tilbake til yrkeslivet. Etter denne gjennomarbeiding på flere plan over tid, kom smerten endelig på avstand. $\mathrm{N}$ oe kunne jeg legge bak meg, og noe kunne jeg leve bedre med. Jeg gjenvant følelsen av mestring og innflytelse over eget liv. Likefullt er det smertefullt å fortelle om dette nå. Det oppveies av håpet om at mine erfaringer kan bidra til en enda større innsikt i suicidalitet blant fagpersoner, og gjennom dette komme andre til nytte.

\section{Biologiska och psykologiska mellansteg}

Den biologiska psykiatrin ser framför allt sambandet mellan psykisk störning, främst depression och suicidalitet. Förmedlande faktorer söks inom neurobio- login. Detta för bort från det öppna mötet med den suicidala patienten i all hennes livsångest. Kognitiv psykoterapi å andra sidan uppmärksammar förmedlande faktorer av psykologisk natur. U ppgiften är att vidga en psykologisk kortslutning (depression slutar ibland med suicid) till en lång berättelse med många mellansteg ( påfrestande situationer ger negativa tankar, som ger dålig självbild och slutligen leder till depression, som ibland slutar med suicid).

\section{Depression ur kognitivt perspektiv}

Depressioner, liksom ångest och andra känslor är från början normala och funktionella. De är varningsklockor, som manar till eftertanke och problemlösning ( $G$ ut, 1989). Därigenom har de ett klart överlevnadsvärde. Det intressanta ur kognitiv syn punkt är inte depressionen (liknande besvär har vi alla då och då) utan de faktorer som upprätthåller, vidareutvecklar och fördjupar den. Tankestrategier, som fungerar dåligt som problemlösare, som är "dysfunktionella", kallas ibland "tankeförvrängningar". Egentligen är det felanvändning av i grunden nyttiga tankestrategier. A tt vanemässigt alltid fästa sig vid negativa upplevelser, sk negativ selektiv perception, är t ex en central tankeförvrängning.

A aron T. Beck och medarbetare studerade samspelet mellan aktuella situationer, framför allt relationer, samt självbild och framtidsupplevelser (Beck, 1967;

Clark et al.,1999). De fann att c:a 2/3 av de negativa värderingarna knöts till självbilden. Denna försvagades därmed successivt och producerade upplevelser av hjälplöshet, hopplöshet och mörk framtid. N egativa spiraler uppstod: En lågt värderad självbild ledde till nya misslyckande, som i sin tur ytterligare försvagade självbilden. Den försvagade självbilden krävde tröst, ibland i former som väckte ny skuld, t ex överutnyttjande av mat, alkohol och sex, med ytterligare försvagad självbild som följd. Detta ledde småningom till en depressionssjukdom.

G enom att systematiskt förstå och förändra dessa psykologiska mellansteg med kognitiva tekniker och värdera effekten med bl a skattningsskal or kan patienten gradvis öka sin förmåga att förstå och hantera sin psykiska störning innan den leder till suicidtankar och suicidförsök. Psykologiska mellansteg kunde senare identifieras mellan ångest och ångestsjukdomar, såsom social fobi, tvångssyndrom och hälsoångest (hypokondri). D et intressanta är också här de faktorer som uppehåller och vidareutvecklar ångesten och gör att den övergår i en ångestsjukdom.

\section{Problemlösning}

Det inre ältandet av de fruktlösa försöken att hantera livet är i själva verket ständigt upprepade och ständigt lika misslyckade försök till problemlösning. A tt generellt öka effektiviteten i personens sätt att lösa problem är därför angeläget. N u finns allmänt accepterade och väl fungerande tekniker för detta. De rymmer problemidentifikation, prioritering, målbeskrivning, framkastande av en mängd tänkbara handlingsvägar, val av det sannolikt mest framgångsrika tillvägagångssättet, systematisk träning i verkliga livet, egen systematisk skattning av resultaten samt etablerandet av strategier för att attackera nya påfrestningar (H awton et.al., 1989; Salkovskis, 2001). Senare forskning har dock visat att suicidala personer inte generellt är sämre på problemlösning utan att de är det i samband med sin depressiva sjukdom.

\section{Fällan}

A tt öka problemlösningsförmågan är en generell teknik. För mer specificitet måste man ställa frågan vad suicidalitet egentligen handlar om. En teoretisk modell för att studera detta utgår från de klassiska metaforerna av att vara instängd i ett hörn eller att ha tunnelseende. Drag i denna preciserades genom erfarenheter av råttors och fåglars revirkamp ( $\mathrm{G}$ ilbert, 1989). På en mänsklig nivå kunde de beskrivas som en upplevelse av att vara instängd. Denna fälla (W illiams, 2001; Williams \& Pollock, 2001) består av tre komponenter: A tt vara en förlorare, att vara instängd och att inte se någon väg ut.

A tt alltid fästa sig vid det negativa skapar upprepade upplevelser av nederlag, som general iseras till satsen "Jag är en förlorare". Känslan av att vara instängd, dvs fäll ans väggar, konstrueras framför allt av den tankestrategi, som kallas 


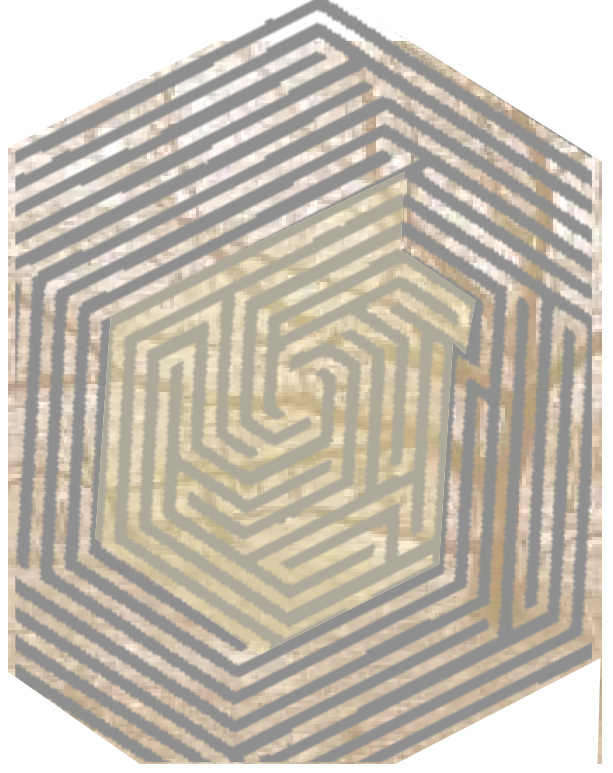

overgeneralized memory, O G M. Detta är ett säkerhetsbeeende som hindrar aktualiseringen av smärtsamma minnen, genom ett generellt motstånd mot allt som konkret och specifikt kan innebära en fara. Personen känner och tänker generellt. Detta skyddar henne från negativa känslor och tankar. M en samtidigt berövas hon de positiva upplevelser som gör livet värt att leva. Detta är fällans väggar. 0 väntat nog visade det sig att den depressiva personen inte bara hade negativa förväntningar på framtiden utan framför allt en oförmåga att föreställa sig positiva mål. U tan positiva framtidsmål bortfaller skälen att leva. För dessa tre moment (vara förlorare, vara instängd och utan väg ut) finns nu specifika analys- och behandlingsmetoder. M ed detta åstadkom forskarna en fördjupad förståelse av suicidalitetens natur. De skapade en metafor i vilken den suicidala personen kan känna igen sig.

\section{Suicidalitet och depressionen är två saker}

Experimentellt har man kunnat visa att suicidtankar är av annan karaktär än depressionen. U tsätts normala människor för sorgsen film, musik eller samtal blir de sorgsna. Detta gäller också personer med tidigare depression, som nu är i friskt skede. $0 \mathrm{~m}$ dessa personer tidigare haft suicidtankar återkommer emel lertid dessa, trots att de inte är deprimerade. En gång etablerade suicidtankar kan således framkallas relativt lätt även i friskt skede.
Detta beror på att suicidaliteten är en kognitiv konstruktion, som uppstått i en pressad situation och sedan lever sitt eget liv vid sidan av en eventuell depressionen.

Ett annat fynd, som talar i samma riktning, är att symtombilden vid återfall $i$ depression varierar starkt. Ena gången dominerar sömnstörning, andra gången skuld- och skamkänslor Osv. D et enda symtom som inte varierar är suicidtankar. $\mathrm{H}$ ar sådana förekommit tidigare återkommer de praktiskt taget alltid på samma sätt (W illiams et al., 2006).

\section{Suicidalitet kan komma före depressionen}

Dessa och liknande fynd ifrågasätter teorin att suicidalitet är ett depressivt symtom: Först depression, sedan suicidalitet. I bland kan det vara tvärtom: Först suicidalitet, sedan depression. I A M S J sin upplevelse uppstod de samtidigt. Självmordet framstod blixtsnabbt och sedan under lång tid som ett självklart och livgivande löfte om befrielse från outhärdlig plåga. Den tanken hade ett tydligt överlevnadsvärde.

En stark upplevelse av den psykiska dödens realitet, $d v$ s förlust av det egna friska psykiska livet, genererade samtidigt en depressiv reaktion. Först var den övervägande tankemässig (kognitiv), men småningom involverades känsla och kropp. Skammen bredde ut sig i kroppen och över hela livet. Först senare blev de depressiva symtomen synliga utåt.

\section{Psykiska skador}

$M$ ånga suicidforskare fokuserar nu på det psykiska traumats betydelse vid uppkomsten av suicidalitet och utvecklandet av ett posttraumatiskt stressyndrom,

PT SD. I ökande utsträckning har de kunnat påvisa samband mellan psykiska trauman och senare suicidalitet (M eichenbaum, 2006). En svårighet forskningsmässigt och kliniskt är att den traumatiska situationen åter måste medvetandegöras, dvs säkerhetsval len måste genombrytas. Detta frigör ångest och ökar under en period risken för suicidala handlingar. Detta kan motverkas genom en trygg allians mellan klient och terapeut.

\section{Psykologisk olyckshändelse}

En följd av detta är att händelser i om- världen börjar få ökad betydelse för förståelsen av hur suicidalitet uppkommer och bibehålls. Denna nya förståel se gäller också själva suicidhandlingarna. Detta omvärldsperspektiv har ju länge gällt inom olycksfallspreventionen, som också inspirerat till suicidprevention (Clarke \& Lester, 1989), t ex genom att bygga skyddsräcken och nät på höga broar eller minska åtkomligheten av giftiga läkemedel. $N$ är olycksfall spreventionen startade för över hundra år sedan ansåg man att olyckshändelserna var betingade av öde eller slump och omöjliga att göra något åt. Senare fann man orsakerna hos enstaka individer, olycksfåglar. Först när man anlade ett systemteoretiskt eller kontextuellt perspektiv kom de stora framgångarna. U tomståen de haverikommissioner har $t$ ex varit avgöran de för eliminering av säkerhetsrisker inom flyget och vägtrafiken. Sådana händelseanalyser sker nu i ökad utsträckning också efter suicid (Socialstyrelsen \& Statens folkhälsoinstitut, 2006). N är det gäller suicid uppfattar vanliga människor ofta att självmord orsakas av öde eller slump. Psykiatrer och många psykoterapeuter har kommit fram till personnivån. Suicidiet beror på psykisk störning, oftast en depression. G enom olycksfal Isperspektivet har vi nu möjlighet att ta steget över till systemnivå. Kanske är det nu de stora resultaten skall komma!

\section{Suicidalitetens språk}

U nder den första tiden efter våldtäkten bevärades A M SJ av en intensiv inre dialog, där olika tankar, nästan som hörbara röster, argumenterade mot varandra. Ä ven suicidhandlingar föregås ofta av en intensiv inre dialog (Firestone, 2006; M eichen baum, 2006) samtidigt med en ökning av den akuta suicidrisken. Stegringar i dialogens intensitet kan markera övergången från en latent, något lugnare, till en episodisk påträngande suicidalitet med hög dödsrisk (Rudd, 2006). Kliniska bedömningar brukar begränsas till den akuta suicidrisken. Därefter återgår emellertid patienten till sin kroniska eller latenta suicidrisk. Vi skulle behöva bättre instrument för att kunna beskriva och möta båda dessa former av suicidrisk.

En tonårsflicka som pressas av tankar att hon inte vill leva eller en familj som 
drabbats av suicid har i stort sett tre ord till sitt förfogande: Självmord, självmordsförsök och självmordstankar. Det räcker inte! Kontrasten mot vägtrafikens språk är skarp. För att kunna föra en bil måste man lära sig hundratal s begrepp om bilen, vägen, omgivande natur och mänskliga ofta irrationella reaktioner. Detta måste integreras så att man reagerar instinktivt i en farlig situation. Suicidalitetens språk behöver bli lika nyanserat som trafikens. Då skulle många dödsfall kunna förebyggas (Beskow et al., 1999; Beskow et al., 2005.)

Trenden i mötet med den suicidala patitenten går mot att mer flexibelt närma sig den suicidala människan och hennes självupplevda behov (M ichel et al., 2002). Detta innebär att stödja utvecklingen av ett fungerande nyanserat språk i suicidala situationer. Detta sker redan t.ex. i dialektisk beteendeterapi, DBT (Linehan, 1993), kognitiv psykoterapi även inneslutande drogmissbrukare (Brown et al., 2005) och i mindfulnessträning i syfte att öka förmågan till självobservation och därmed förhindra recidiv i depressionssjukdom (Segal et al., 2001).

\section{Välkommen tillbaka}

A tt se suicidaliteten som en i grunden normal kognitiv funktion som kan övergå i destruktivitet, att orsakerna delvis är verkliga, både svårt traumatiska och banalt obetydliga slumpmässigt inträffade händelser, psykologiska olycksfall, både i processens början och dess slut, och att den suicidala personen behöver få stöd att utveckla ett rikt differentierat språk, suicidalitetens språk, för att bättre kunna medvetandegöra och förändra sina upplevelser, är tre tendenser i dagens suicidprevention. De erbjuder en hoppingivande komplettering av det psykopatologiska perspektivet med ett normal psykologiskt språk och ett systemteoretiskt sätt att se. Sammantagna reser de frågor om vi inte möjligen är på väg mot en ny mer realistisk förståelse av suicidaliteten och dess natur.

De innebär dessutom att den suicidala personen välkomnas som en helt jämbördig samarbetspartner befriad från onödig skuld och skam. 0 ckså detta "välkommen tillbaka från 1.700 år i exil" är rimligt att uppfatta som del i denna nya förståelse.

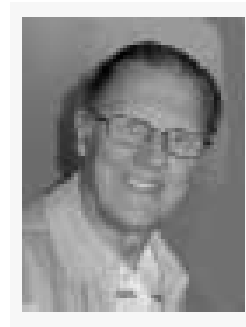

Jan B eskow är professor, specialist i psykiatri och socialmedicin, suicidforskare, ordförande i Västsvenska $N$ ätverket för Suicidprevention samt utvecklingskonsult vid Center för C ognitiv Psykoterapi och $\mathrm{U}$ tbildning i G öteborg.

Senaste bok: Suicidalitetens språk. 2005.

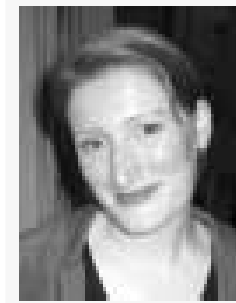

A nne M arie S. Johnsen har vært ansatt ved N orsk Folkemuseum, undervisningsseksjonen, siden 2003. Studier i kunsthistorie, engelsk og musikk. Bakgrunn fra teater og pedagogisk virksomhet. U nder behandling ved distriktspykiatrisk poliklinikk fra høsten 2000 til våren 2003.

\section{Referanser}

Beck, A .T. (1967). D epression. C auses and treatment. Philadelphia: U niversity of Pennsylvania. Press.

Beskow, J. (1979). Suicide and mental disorder in Swedish men. A vh. A cta Psychiatr Scand suppl. 277. Köpenhamn: M unksgaard.

Beskow, J. (1982). Longitudinal and transactiona perspectives on suicidal behaviour. Experiences of suicide prevention in Sweden. In A chté, K., $\mathrm{N}$ ieminen, K., \& Vikkula, J. Suicide Research II. Proceeding of the symposium on suicide research by the Yrjö Jahnsson foundation. H elsinki: Psychiatrica Fennica, suppl.

Beskow, J., Eriksson, B.E., \& N ikku, N . (1999) Självmordsbeteende som språk. Stockholm: Forskningsrådsnämnden, R apport 99:2.

Beskow, J.,\& Jarrick, A . (red). (2000). H umanistisk suicidprevention. Stockhol m: Forskningsrådsnämnden, Rapport 2000:3.

Beskow, J., Palm Beskow, A ., \& Ehnvall, A . (2005) Suicidalitetens språk. $L$ und: Studentlitteratur.

Brown, G .K., Ten H ave, T., H enriques G .R., Xie, S.X., H ollander, J.E., Beck A .T. (2005). C ognitive therapy for the prevention of suicide attempts. A randomized controlled trial.

JA M A 294, 5, 563 - 570.

Clark D, Beck A .T. \& A lford B (1999). Scientific foundations of cognitive theory and therapy of depression. $N$ ew York: John Wiley \& Sons.

Clarke, R., \& Lester, D. (1989). Suicide: Closing the exits. N ew York: Springer-Verlag.

Ellis T.E. (ed). (2006). Cognition and suicide. Theory, research, and therapy. W ashington: A merican Psychological A ssociation.

Firestone L. (2006). Suicide and the inner voice. Chap. 7 in EllisT. Cognition and suicide. Theory, research and therapy. Washington: A merican Psychological A ssociation.
G ilbert, P. (1989). H uman nature and suffering. $\mathrm{H}$ ove and London: Lawrence Erlbaum A ssociates

$G$ ut, E. (1989). D en sunda depressionen. Möjligheter och svårigheter i dess förlopp. Stockholm: Wahlström \& W idstrand.

H awton, K.A ., Kirk, J., and Clark, D.M . (eds.)

(1989). Cognitive behaviour therapy for psychiatric problems. A practical guide. Oxford: O xford U niversity Press.

Linehan M .M . (1993). C ognitive-behavioral treatment of borderline personality disorder. N ew York: Guilford Press.

M eichen baum D. (2006). Trauma and suicide: A constructive narrative perspective. Chap. 15 in Ellis T. Cognition and suicide. Theory, research and therapy. W ashington: A merican Psychological A ssociation.

M ichel, K., M altsberger, J.T., Jobes, D.A ., Leenaars, A .A ., Orbach, I., Stadler, K., Dey, P., Young, R.A ., Valach L. (2002). C ase Study. D iscovering the truth in attempted suicide. A m J of Psychotherapy, 56, 3, 424-437.

Pokorny A .D. (1974). A scheme for classifying suicidal behaviors. In Beck, A .T., Resnik, H .P.L. $\&$ Lettieri D.J. (eds.). The prediction of suicide. Bowie: The $\mathrm{C}$ harles Press Publ. Inc.

Retterstøl, N ., Ekeberg Ø ., \& M ehlum L. (2002) Selvmord - et personlig og samfunnsmessig problem. 0 slo: $G$ yldendal A kademisk.

Rudd D. (2006). Fluid vulnerability theory: $A$ cognitive approach to understanding the process of acute and chronic suicide risk. Chap. 16 in Ellis T. Cognition and suicide. Theory, research and therapy. W ashington: A merican Psychol A ss.

Salkovskis P.M . (2001). Psychological treatment of suicidal patients. In W asserman, D. Suicide an unnecessary death. Hove and London: $M$ artin Dunitz.

Segal, Z.V., Williams J.M.G., \& Teasdale, J.D. (2002). M indfulness-based cognitive therapy for depression: A new approach to preventing relapse. $\mathrm{N}$ ew York : G uilford.

Socialstyrelsen \& Statens Folkhälsoinstitut (2006). Förslag till nationellt program för suicidprevention - befolkningsinriktade och individinriktade strategier och åtgärdsförslag. Stockholm: Socialstyrelsen.

Vea, I. (2006). D ødelig skam. Suicidologi, $11,1,19-20$.

Williams, M., \& Pollock L. (2001). Psychological aspects of the suicidal process. In van $\mathrm{H}$ eeringen K. (ed). U nderstanding suicidal behaviour. The suicidal process approach to research, treatment and prevention. Chichester: Wiley.

W illiams, M . (2001). Suicide and attempted suicide. $\mathrm{N}$ ew edition. London: Penguin.

W illiams JM , C rane C, Barnhofer T, Van der Does A J, Segal ZV. (2006). R ecurrence of suicidal ideation across depressive episodes. 」 A ffect Disord, 91(2-3), 189-94 